\title{
Políticas públicas e desigualdades na migração e refúgio'
}

\author{
Carmem Lussi* \\ Consultora em migrações e direitos humanos. Brasília, DF, Brasil
}

Resumo: $\mathrm{O}$ artigo analisa, como desafio para as políticas públicas, o tema da alteridade de migrantes e refugiados, quando esta é vivida ou interpretada como diferença que discrimina, exclui ou até criminaliza, transformando sua riqueza em desigualdade que produz e reproduz vulnerabilidades. Após ampla introdução, o texto se desenvolve em três partes: contribuições ao tema a partir do Relatório Mundial 2013 da Organização Internacional para as Migrações (OIM) sobre as Migrações e a partir do Documento Final do II Diálogo de Alto Nível das Nações Unidas sobre Migrações e Desenvolvimento de 2013, às quais segue um aprofundamento sobre a criminalização das migrações, considerado um aspecto que determina a abordagem do tema. A breve conclusão sublinha a relevância do reconhecimento dos sujeitos migrantes e refugiados como protagonistas na formulação das políticas migratórias igualitárias.

Palavras-chave: migrações, direitos humanos, desigualdades, políticas migratórias.

\section{Algumas premissas}

Entre os desafios que migrantes e refugiados enfrentam no Brasil estão formas e situações em que as desigualdades de que são portadores se transformam em fatores de exclusão ou de discriminação. A sugestão do tema das desigualdades pelos organizadores do evento "Desigualdades, deslocamentos e políticas públicas na imigração e refúgio" como porta de entrada para tratar o tema das políticas migratórias é indicativo de uma visão do tema na perspectiva dos direitos humanos, a saber, uma perspectiva a partir das vulnerabilidades que migrantes e refugiados podem enfrentar em suas trajetórias no Brasil.

Não existe a igualdade em contextos de pluralidade sociocultural, menos ainda em contextos onde sujeitos migrantes interagem com autóctones, por vezes convergem e sempre se cruzam na luta por políticas públicas adequadas e, possivelmente, formuladas para garantirem equidade de tratamento e de acesso a direitos, bens e serviços. Homens e mulheres migrantes, em sua condição de estrangeiros, representam uma diferença imprescindível nos contextos locais onde buscam inserir-se, normalmente, como concidadãos "iguais" a todos os demais habitantes de um determinado território. Consideramos aqui o termo "desigualdades" com um sentido amplo, referido a situações ou

1 Uma primeira versão deste texto, aqui ampliado, foi apresentada no Seminário Internacional "Desigualdades, deslocamentos e políticas públicas na imigração e refúgio" realizado nos dias 8 e 9 de novembro de 2013 na Biblioteca do Memorial da América Latina em parceria entre o Departamento de Psicologia Clínica do Instituto de Psicologia da USP e o Programa de Pós-Graduação em Psicologia Social - PUC-SP. A parte sobre criminalização da migração foi apresentada no Seminário "A criminalização das migrações e a proposta para o novo Código Penal Brasileiro" realizado no dia 12 de novembro, no Auditório do UniCEUB - Brasília/DF, em parceria entre o CSEM - Centro Scalabriniano de Estudos Migratórios e o Centro Universitário UniCEUB.

* Autora correspondente: carmem.lussi@gmail.com características pessoais ou coletivas, sociais ou culturais que determinam a presença de alguma forma de alteridade em uma relação ou em um contexto específico, em que a alteridade é interpretada e utilizada como desvantagem para os sujeitos que a vive ou representa e até mesmo leva a tratar tais sujeitos com discriminação ou exclusão.

As desigualdades que discriminam e excluem têm relação com a vulnerabilidade que expõe os sujeitos à exclusão. Ser migrante ou refugiado, por si só, não significa ser vulnerável, mas a migração pode representar uma condição que favorece e até leva a pessoa a passar por situações de vulnerabilidade, como as que são favorecidas pela exaltação da especificidade migratória, assim como acontece também onde se verifica a negação das diversidades que os sujeitos que migram levam consigo. Políticas públicas para migrantes podem fortalecer as desigualdades, enquanto a inclusão da população migrante e refugiada nas políticas públicas pensadas em uma perspectiva integral e transversal favorece a integração e a prevenção de violações de direitos. Desigualdade não se combate com igualdade; se previne com equidade.

As desigualdades podem ser registradas nas mais variadas realidades tais como em relações interpessoais ou profissionais, no acesso a serviços ou no reconhecimento de direitos. Não é objetivo deste texto um aprofundamento teórico; o interesse é oferecer elementos para abordar o tema da equidade para migrantes e refugiados, em um momento importante de reflexão sobre políticas migratórias e direitos humanos no País. Assumimos que a desigualdade existe como um elemento contingente a ser considerado para pensar políticas públicas na perspectiva dos direitos humanos, sem pretensão de buscar alguma forma de igualdade niveladora, pois a alteridade que migrantes e refugiados aportam às sociedades de destino é fator de enriquecimento para todos os atores que as integram, não sem riscos de conflitos, por causa da intrínseca complexidade 
dos processos multiculturais. Entretanto, a desigualdade pode ser também ato ou sintoma de discriminação e, como tal, requer análises profundas e políticas corajosas para que sejam capazes de ação incisiva.

Após ampla introdução, o artigo apresenta elementos de reflexão a partir de alguns textos de referência no debate internacional recente sobre migrações em relação ao desenvolvimento humano e à promoção e defesa dos direitos humanos de migrantes e refugiados. $\mathrm{O}$ artigo oferece também alguns elementos sobre um efeito perverso muito específico das desigualdades que interferem nos processos de migração e de refúgio que é conhecido como "criminalização das migrações".

\section{Políticas migratórias "sem desigualdades"}

A discussão sobre as desigualdades enfrentadas por migrantes e refugiados requer uma visão abrangente sobre as políticas migratórias. Estas não são somente as políticas que respondem à questão sobre quem pode ou não entrar no Brasil e em quais condições. A política migratória inclui também toda a preocupação para que a população migrante que escolheu o Brasil para viver tenha acesso às políticas públicas universais, pensadas e implementadas no país, além de ações, programas e políticas que enfrentam os desafios específicos da população migrante ${ }^{2}$.

As desigualdades existem como um elemento da realidade e determinam um contexto local. Estas são representadas por excelência pelos sujeitos que migram, mas podem referir-se igualmente a sujeitos autóctones e podem requerer políticas específicas para que os direitos possam ser garantidos. O Brasil está em seus primeiros passos nas respostas às demandas específicas da população migrante, está aprendendo com os novos fluxos que já não se assimilam anonimamente aos tecidos sociais como por vezes aconteceu com fluxos menores, no passado recente. É uma aprendizagem que leva a reinventar a relação da população autóctone e de seu governo com pessoas, famílias e grupos de imigrantes para além do que foi a migração histórica, que hoje é sentida como uma experiência distante cultural e socialmente. Essa reinvenção marca a abordagem com que os temas relativos à mobilidade humana são tratados e a capacidade de pensar, planejar e implementar serviços que representam e fomentam o acesso a direitos e processos progressivos de cidadania para toda a população, sem exclusão de quem nasceu em outro país.

Cabe lembrar, entretanto, que o fenômeno migratório normalmente dá visibilidade a eventuais desigualdades e incongruências nas políticas públicas. Por exemplo, os

2 Um abrangente relatório com demandas e sugestões sobre políticas migratórias no Brasil foi compilado em maio de 2013, em eventos de diálogo social ampliado sobre direitos humanos na política migratória com atores do governo e da sociedade civil, incluindo migrantes, acadêmicos e instituições que atuam em serviços de atendimento direto. O Relatório Geral dos Eventos de I Nível do Projeto OIM - DEEST/SNJ está disponível em http://brasil.iom.int/images/estudio/Relatorio $\% 20$ dos $\% 20$ Coloquios $\% 20$ sobre $\% 20$ direitos $\% 20$ humanos $\% 20$ na $\% 20$ politica\%20migratoria\%20brasileira.pdf. Acesso em 23 set. 2014. casos de estrangeiros vítimas de trabalho escravo indicam que neste País ainda persistem problemas na fiscalização do trabalho, ainda existem situações de vulnerabilidade social que as políticas não estão conseguindo identificar e abordar corretamente, e indicam, também, que ainda há exploração do trabalho e violações de leis trabalhistas básicas, entre outros indicadores que uma análise atenta poderia fazer emergir. Tais casos não são simplesmente um problema migratório, apesar de revelarem que a migração pode ser um fator a mais de risco a ser considerado. Pessoas estrangeiras que se encontram em determinadas situações de vulnerabilidade, como é o caso da condição migratória irregular, do isolamento por não conhecimento do idioma ou por formas de exclusão social ou cultural, podem estar mais expostas aos riscos de violações de direitos por causa de suas desigualdades não reconhecidas pelas políticas públicas.

A especificidade de políticas públicas que as desigualdades da condição de migrante ou de refugiado podem requerer permite que eventuais situações de vulnerabilidade precedentes à migração não se agravem por causa do fato migratório e que potencialidades dos sujeitos migrantes não sejam negadas nem fragilizadas. Tal visão permite que governos e comunidades locais façam que a migração seja igualmente benéfica para os migrantes e para os países, pois a migração é e pode ser reconhecida pelas pessoas e pelos governos como um fator essencial para o desenvolvimento social e econômico equitativo, inclusivo e sustentável (Ban Ki-Moon, 2013).

A reflexão sobre as desigualdades enfrentadas pelos sujeitos da mobilidade humana tem a ver com o bem-estar de indivíduos, não menos que com políticas e metas globais. A seguir são retomados alguns elementos de dois documentos recentes que inspiram e favorecem uma visão mais abrangente sobre o tema: o Relatório Mundial 2013 da OIM sobre as Migrações (RMM) e o Documento Final do II Diálogo de Alto Nível da ONU sobre Migração e Desenvolvimento.

\section{O bem-estar das pessoas que migram}

O RMM tratou o tema do bem-estar dos migrantes, com o foco no elemento humano para a abordagem da temática migratória. Entre os cinco eixos apontados pelo RMM como sendo determinantes no debate mundial sobre migração e desenvolvimento, podem ser destacados três ${ }^{3}$ que indicam, em modo particular, pistas para políticas públicas inclusivas da população migrante:

1. Os migrantes como elemento central do debate: refere-se à necessidade de superar o interesse focado unicamente nas dinâmicas socioeconômicas dos países na abordagem da temática migratória, para incorporar a dimensão experiencial a vida dos próprios migrantes.

3 Os outros dois eixos apontados pelo RMM são: a migração não é somente um movimento Sul-Norte; e o fato que a migração fomenta o desenvolvimento humano, porém muitos migrantes não conseguem alcançar um nível satisfatório de bem-estar (OIM, 2013, pp. 23-27). 
Tal enfoque permite identificar e considerar as repercussões da migração na vida dos migrantes e a incidência da migração como fator de desenvolvimento para todos os atores, quem migra e quem é direta ou indiretamente afetado pelos movimentos populacionais. Essa atenção pode abrir portas para uma nova formulação das políticas mais adequadas às realidades humanas implicadas no fenômeno migratório e, portanto, mais capazes de valorizar a migração como um fator humano e social que, bem gerenciado, empodera seus atores e enriquece as sociedades envolvidas. $\mathrm{O}$ foco no elemento humano em se tratando de migrações e refúgio é âncora primordial para garantir que a temática migratória seja tratada na perspectiva dos direitos humanos e não simplesmente na ótica da segurança nacional nem do protecionismo do mercado de trabalho, supostamente reservado preferencialmente aos autóctones, entre outras abordagens prejudiciais aos sujeitos que migram, não menos que à qualidade humana e intercultural das sociedades que os recebem.

2. Desenvolvimento significa também bem-estar humano. A migração fomenta o desenvolvimento humano, porém muitos migrantes não conseguem alcançar um nível satisfatório de bem-estar (financeiro, físico, laboral, comunitário e social). A leitura do fenômeno migratório que considera o tema das desigualdades de fato e a consideração das mesmas na elaboração de políticas, assim como as desigualdades fomentadas socialmente por formas de exclusão e discriminação, cruza com o tema das perdas e dos ganhos do fato migratório. A complexidade do tema não permite soluções rápidas nem fáceis, mas o foco nos sujeitos e a adoção de um conceito de desenvolvimento integral que inclui o desenvolvimento humano de todos os grupos que compõem uma determinada sociedade, inclusive os que representam alteridades ao seu interno, pode favorecer e até garantir direitos e dignidade. No caso específico da mobilidade humana, ela beneficia migrantes e refugiados, promovendo a valorização positiva dos processos ligados à migração. Por vezes e em determinadas condições, a migração se transforma em fator de vulnerabilidade; entretanto, mesmo em presença de perdas e percalços, migrantes e refugiados com suas bagagens e com a experiência migratória não só não podem ser excluídos dos resultados e benefícios do esforço comum de desenvolvimento, mas contribuem exatamente através de sua experiência migratória a um enriquecimento que é ganho para todos. Segundo a OIM (2013), o

bem-estar é uma combinação de amor que sentimos pelo que fazemos a cada dia, a qualidade de nossas relações, a segurança de nossas finanças, o vigor de nossa saúde física e o orgulho que sentimos pelo que aportamos às nossas comunidades. Porém, sobretudo, tem a ver com o modo em que estes cinco elementos interagem. (p. 116)
Estes são os elementos universais do bem-estar que fazem a diferença entre uma vida feliz e uma vida de sofrimento.

3. A agenda para depois de 2015: qual bem-estar para os migrantes? O bem-estar dos sujeitos que migram é determinante para a sustentabilidade a médio e longo prazo, seja do desenvolvimento, seja da própria migração. Há de se considerar que a migração é um fenômeno humano, não uma emergência situacional, apesar de casos emergenciais serem registrados muitas vezes, tanto no Brasil quanto no exterior. E como fator intrínseco do desenvolvimento, os deslocamentos de pessoas e de grupos precisam ser abordados transversalmente e com visão de médio e longo prazo, seja em nível global, seja na elaboração de políticas ou na programação de ações e análises em contextos locais. O desafio é proporcional ao potencial; contudo, a não inclusão do tema transforma potencial em ameaça, o que pode levar sempre mais o tema da migração e o do refúgio para as mesas de gestão de problemas, com custos humanos, sociais, financeiros e também ecológicos que podem ser relevantes.

Será preciso contar com uma base empírica muito mais sólida para compreender adequadamente os vínculos entre a migração e o desenvolvimento. A migração de pessoas tem um efeito acumulativo, em escala nacional, e pode ter repercussões sobre a situação econômica dos países de origem e de destino. A migração pode dar lugar a uma corrente de desenvolvimento que se inicia pelas pessoas, passa pelas famílias e comunidades, até atingir os países. (OIM, 2013, p. 31)

O RMM alerta para o "reconhecimento cada vez mais generalizado de que a migração canalizada e gerenciada eficazmente pelos encarregados da formulação de políticas pode contribuir ao desenvolvimento" (OIM, 2013, p. 35). Isto significa que a força positiva que as migrações podem representar para o desenvolvimento e o enriquecimento integral de um povo ou de uma nação está intrinsecamente relacionada à implementação de políticas adequadas e abrangentes a ponto de alcançar igualmente a população migrante quanto os nativos (OIM, 2013).

Este desafio não exime os Estados de abarcar, no estudo e na concretização de políticas públicas de inclusão e superação das desigualdades discriminatórias, aqueles migrantes que, por diferentes motivos, encontram-se em situação migratória irregular. Cabe citar aqui o Global Migration Group (GMG), que sublinhou a necessidade de pessoas e governos não medirem esforços para remover as causas que pressionam ao aumento da migração irregular. A mensagem de setembro de 2010 do GMG sobre os direitos humanos de migrantes em situação migratória irregular convocou os Estados a trabalhar para assegurar que suas leis e normas estejam de acordo com e promovam os 
padrões e as garantias internacionais de direitos humanos em todas as etapas do processo migratório.

\section{Diálogo de Alto Nível das Nações Unidas sobre Migrações}

Em outubro de 2013 realizou-se, em Nova York, o segundo Diálogo de Alto Nível das Nações Unidas sobre Migração e Desenvolvimento. A preparação do evento aconteceu ao mesmo tempo em que muitas organizações no mundo refletiam sobre a agenda para o desenvolvimento pós-2015, para a qual foi insistentemente recomendada a inclusão da temática migratória, numa tentativa de assegurar a transversalidade da temática para os temas do bem estar, do desenvolvimento e da paz para todos.

O Diálogo de Alto Nível foi preparado por amplo processo de consultas que viu, mundialmente, a participação de governos, organismos internacionais, sociedade civil engajada com o tema e, especialmente, os migrantes. O documento em preparação do II Diálogo de Alto Nível, que recolhe as propostas da sociedade civil organizada que milita na promoção e defesa dos direitos humanos dos migrantes na América do Sul (Espacio Sin Fronteras, 2013), parte do princípio de que todas as pessoas têm direitos, independente de sua condição migratória e, portanto, junto do direito de migrar, assim como o de não ter de migrar, afirma o repúdio à instrumentalização do migrante exclusivamente como mão de obra. A reivindicação expressa no documento sugere que as dificuldades enfrentadas pelos migrantes na conjuntura internacional atual apontam para a necessidade de "formular um novo paradigma de desenvolvimento humano integral que se caracterize pela equidade, o bem-estar, a democracia e a corresponsabilidade". Neste novo paradigma tem um papel primordial a informação, que orienta, empodera e favorece o reconhecimento da indivisibilidade dos direitos humanos, assim como o respeito da vida e da dignidade dos migrantes, por parte de todos os atores, o que pode também prevenir as desigualdades, a discriminação e a criminalização da migração.

O texto final com as contribuições da sociedade civil do mundo inteiro para o II Diálogo de Alto Nível sobre Migração e Desenvolvimento também faz referência explícita à necessidade da equidade entre os princípios que regem as políticas públicas dos governos para a busca de um modelo de desenvolvimento que integre as características, as exigências e as contribuições dos sujeitos e dos processos das migrações internacionais nos processos de construção de leis e políticas de população e de desenvolvimento.

Para determinar o lugar da migração na agenda pós-2015, os Estados têm a oportunidade não somente de valorizar as contribuições dos migrantes para os Países de origem e de destino, mas também de explorar as possibilidades de uma política coerente, capaz de fazer da migração uma escolha e não tanto uma necessidade, e de considerar modelos alternativos de desenvolvimento que priorizam os direitos humanos, a igualdade, a dignidade e a sustentabilidade. (Global Coalition on Migration, 2013, p. 6)

Entre as 34 proposições da Declaração Final do evento, há elementos que apontam para políticas migratórias que vão além da atenção às fronteiras e ao estabelecimento de critérios para entrada e fixação no território, incluindo temas como integração, interculturalidade e desenvolvimento humano. Seguem breves referências ao texto, como uma lista de proposições ou pistas para itinerários de construção de estudos e elaboração de políticas migratórias"

- Migração é uma realidade pluridimensional e "deve ser tratada de forma coerente, ampla e equilibrada, integrando o desenvolvimento com a devida consideração das dimensões social, econômica e ambiental, assim como o respeito dos direitos humanos" (n. 1);

- O fortalecimento institucional é um aspecto fundamental para que o tema migratório seja integrado "de modo eficaz e inclusivo" e no respeito dos direitos humanos, no planejamento do desenvolvimento do país (n. 2);

- A promoção e a proteção efetiva dos direitos humanos e das liberdades fundamentais de todos os migrantes devem ser asseguradas independentemente da condição migratória, com atenção especial a mulheres e crianças, "evitando aplicar enfoques que podem exacerbar suas vulnerabilidades" (n. 10);

- A possibilidade efetiva de migração "segura, ordenada e regular" é fundamental para evitar tráfico de pessoas, contrabando de migrantes e migração irregular (n. 18);

- Faz-se necessário aprofundar a interação entre os governos e a sociedade civil para encontrar respostas aos desafios e às oportunidades que as migrações internacionais promovem (n. 21);

- Uma acolhida adequada aos migrantes retornados é considerada um dever dos Estados, que se conjuga com o direito ao retorno (n. 24);

- A produção de dados estatísticos confiáveis sobre as migrações é imprescindível para a formulação de políticas sustentáveis em todos os aspectos das migrações internacionais relacionados com o desenvolvimento (n. 28).

\section{Desigualdades e criminalização dos migrantes}

Os estudos e os debates sobre migrações e direitos humanos vêm chamando a atenção para um aspecto crucial no tratamento da temática: a criminalização das migrações. Entre as muitas formas, declaradas ou sutis, em

4 As traduções entre aspas a seguir são da autora, realizadas a partir da versão oficial em espanhol. 
que a criminalização se apresenta, podem ser identificadas ao menos três configurações em que a criminalização se expressa e é fomentada:

a. a que a lei estabelece tipificando o crime da irregularidade migratória;

b. a que os estereótipos preconceituosos favorecem através de um discurso público ou midiático de que os migrantes praticam mais crimes do que os nacionais; $\mathrm{e}$

c. uma mais sutil, consequência de políticas restritivas e discriminatórias que, rejeitando os migrantes e refugiados, ao mesmo tempo que pode empurrá-los para os circuitos do crime, leva os sistemas repressivos a identificar, prender e condenar mais facilmente um estrangeiro do que um cidadão nacional pelo mesmo crime ou até a aplicar sanções mais fortes, no caso dos migrantes.

A criminalização da irregularidade migratória acontece quando a lei pune como crime a condição migratória irregular de um estrangeiro no território, em vez de tipificar o ato como infração, o que colocaria a pessoa em situação considerada irregular, não ilegal. A migração irregular é um tema a ser tratado na esfera administrativa, não penal. Alguns países tipificam o crime de "entrada irregular no país", que tem relação com contrabando de imigrantes, em que os criminosos são os que violam leis e normas para favorecer a entrada irregular de uma pessoa no território nacional. A criminalização dos migrantes se refere à perseguição penal dos sujeitos que entram irregularmente, enquanto que o crime de contrabando de migrantes criminaliza e persegue penalmente quem facilita, não sem ganhos, a entrada irregular de estrangeiros.

Considerar crime a presença irregular de uma pessoa no território intensifica sua condição de vulnerabilidade, podendo comprometer a garantia de respeito de seus direitos básicos, como pessoa humana. Definir que a irregularidade migratória é crime gera uma situação de insegurança para os sujeitos que se encontram em tal condição, expondo-os à violação de seus direitos. Segundo o Comissário pelos Direitos Humanos do Conselho da Europa,

o interesse dos Estados em controlar as próprias fronteiras é legítimo, mas a criminalização é uma medida desproporcional que fortalece os estigmas e a marginalização da população migrante. As infrações em matéria de imigração deveriam ser de natureza administrativa. (Hammarberg, 2009, p. 18)

O Comissário solicita aos Estados, antes de tudo, que não seja utilizado o termo "imigrante ilegal", porque se trata de um termo contraproducente e que reproduz um engano, pois as pessoas não são ilegais. Seu status perante as autoridades estatais pode não ser regular, mas isto não torna una pessoa menos humana. Hammarberg (2009) afirma que há pelo menos dois aspectos mais preocupantes em que se registram formas de criminalização dos migrantes: o primeiro é que as medidas adotadas podem separar os estrangeiros dos cidadãos nacionais, submetendo os primeiros a práticas que não podem ser aplicadas aos segundos, como a prisão sem imputação. Em segundo lugar, a criminalização dos migrantes leva a criminalizar as pessoas que se relacionam com imigrantes, deixando assim o recado que o contato com os estrangeiros pode ser arriscado e trazer problemas com a justiça. Tudo isso também multiplica a criminalização na sociedade, aumentando a discriminação contra as pessoas suspeitas de serem estrangeiras, favorecendo assim a xenofobia e o racismo.

Políticas de criminalização de migrantes incidem de modo determinante na compreensão que os povos adotam sobre a migração. A abordagem à temática migratória que criminaliza a irregularidade também fomenta uma mentalidade restritiva para o acesso a serviços "públicos". Quando a criminalização é adotada no discurso público ou na lei, a premissa adotada como pressuposto é que todo estrangeiro é potencialmente um criminoso até que demonstre que dispõe de um regular documento autorizando a permanência no país. A abordagem favorece uma mentalidade difundida de criminalização de todos os migrantes, não só os que estão em situação irregular. Quem vive em situação irregular onde há criminalização, caso sofra algum crime, não tem real possibilidade de pedir ajuda, de denunciar e até mesmo de tornar pública a agressão ou o abuso a que for submetido, por medo de represálias .

Criminalização e securitização da política migratória estão relacionadas e são interdependentes: onde há criminalização dos migrantes, a ideia de que os estrangeiros atentam contra a segurança da população autóctone é facilmente levada a formas de marginalização dos estrangeiros, favorecendo comportamentos xenófobos que os excluem da população que tem direito a segurança publica, e os expõe ao risco de ser tratados como "bodes expiatórios" dos problemas da segurança pública.

Tipificar como crime a imigração irregular não vai interromper os fluxos irregulares se não existirem canais para fluxos regulares para que incluam as populações normalmente excluídas dos fluxos de entrada previstos na lei, sobretudo quem emigra em busca por melhores condições de vida.

A Comunidade dos Estados da América Latina e do Caribe (CELAC) rejeitou a criminalização dos migrantes junto às Nações Unidas - no Diálogo de Alto Nível sobre Migrações e Desenvolvimento de outubro de 2013, inclusive para migrantes em condição migratória irregular (Granma Internacional Digital, 2013). A CELAC argumentou que a criminalização dos migrantes atenta contra o respeito, a dignidade e os direitos humanos e não assegura as liberdades fundamentais, o que se constituiu uma ameaça à vida dos sujeitos que vivem em situação migratória irregular em um país que criminaliza a migração. De fato,

\footnotetext{
5 Sobre este tema existe uma Opinião Consultiva importante da Corte Interamericana de Direitos Humanos, apesar de ser pouco conhecida. Breve apresentação da OC-18/03 pode ser lida em Uzeta (n.d.).
} 
a criminalização deteriora as condições de vida dos migrantes e suas famílias, aumentando processos de exclusão nas sociedades de chegada, o que impede sua integração e a coesão social.

A criminalização pode ser expressa também pelo tratamento discriminatório da lei ou das políticas quando estas exigem de migrantes condições e comportamentos que não são exigidos dos nacionais ou vice-versa e proíbem a estrangeiros comportamentos e condições admitidas e até promovidas para os nacionais, como é o caso da proibição de reuniões coletivas para manifestações públicas e a interdição de assinar editorial. Este tipo de resistência foi exemplarmente contestada pela campanha A Day without Immigrants, de $1^{\circ}$ de maio de 2006, nos Estados Unidos, entre outras menos conhecidas, nas quais migrantes regulares e irregulares assumiram uma subjetividade política que revela a insuficiência de uma abordagem criminalizadora da migração (Nyers, 2010).

A criminalização da migração relacionada com a criminalidade praticada pelos migrantes tem, ao menos, duas linhas teóricas que ajudam a interpretar o fenômeno. Por um lado, estudiosos consideram que a criminalização aumenta os índices de casos de crimes praticados por migrantes; por outro, pesquisadores analisam que a criminalização das migrações incide no modo como é feito o tratamento dos dados e das informações (inclusive da mídia) que fazem aumentar os números de casos de crimes atribuídos aos migrantes através do aumento de migrantes denunciados, condenados e encarcerados (Martino \& Santero, 2010).

$\mathrm{O}$ aumento da criminalidade entre migrantes é diretamente proporcional às políticas e práticas que criminalizam social e culturalmente os migrantes e refugiados, o que de fato dificulta sua inserção social e trabalhista, o acesso à moradia com dignidade $\mathrm{e}$ a integração na sociedade de destino. Tais resistências favorecem o envolvimento de migrantes com sujeitos e ambientes marginalizados e o aliciamento em redes de criminosos, especialmente para a droga e para pequenos crimes, especialmente entre migrantes irregulares (Barbagli, 2008). Dal Lago (1998) sustenta que a criminalização dos migrantes é uma profecia que se autorrealiza, pois expressa uma "invenção do inimigo público" nas falas narrativas, retóricas, políticas, burocráticas, midiáticas e até mesmo sociais, que contribuem para a marginalização dos migrantes, tornando-os homogeneamente "não-pessoas". Este aspecto da criminalização é estreitamente relacionado com a construção social da imigração como problema de segurança. A criminalização adota o ódio como estratégia social de resistência e não reconhecimento da migração como fenômeno humano. E, enquanto uma dimensão do humano, é um fenômeno socioeconômico, cultural e político, não uma questão penal.

Ambrosini (2005) e Melossi (2008) apontam alguns fatores socioeconômicos que incidem no aumento da criminalidade entre migrantes e que podem fortalecer a percepção social que favorece sua criminalização: a marginalização social e a pobreza; a inserção dos migrantes em setores da economia informal, perigosos e não qualificados, ligados a processos de inferiorização e racialização; o efeito de redes ou de correntes familiares ou migratórias que podem levar a networks ilegais; e as dificuldades de acesso aos serviços básicos, unidos a uma maior acessibilidade aos circuitos ilícitos, especialmente para quem só conseguiu entrar no país por percursos irregulares.

A criminalização da migração tende a forçar os migrantes a buscar formas alternativas de mobilidade social, especialmente no caso de quem vive em situação irregular no país e que, portanto, mais facilmente torna-se vítima de crimes, sem efetiva possibilidade de recorrer ao sistema de justiça por conta da própria condição migratória. $\mathrm{O}$ melhor modo para combater a criminalização dos migrantes é pensar uma lei sobre migrações que preveja a efetiva possibilidade de imigração regular, acompanhada de políticas de integração. Neste esforço, um dos principais aportes dos estudos acadêmicos está no trato - o menos racista possível - dos dados estatísticos sobre migração e sobre crimes praticados por migrantes.

Enfim, a criminalização referida à difusão e ao fortalecimento de estereótipos negativos contra a imigração em geral. Este tipo de criminalização é o mais conhecido e se expressa em falas informais, discursos, mensagens nas redes sociais, linguagem dos textos de artigos e matérias em canais de informação, entre outras. São os discursos de rejeição da imigração ligados ao protecionismo do mercado de trabalho a ser reservado aos trabalhadores nacionais ("roubam nossos empregos"); as falas que difundem a rejeição aos estrangeiros acusando-os de responsabilidade por suposta insustentabilidade dos serviços básicos como saúde e educação de base, sem considerar que a maioria dos migrantes entra no país já "pronto para o mercado de trabalho", iniciando a contribuir com taxas e impostos que entram nos cofres públicos a benefício de toda a população, mesmo sem ter gasto nada de recursos do país para nascer, crescer ou estudar, por exemplo; e até a falácia baseada no estereótipo do Brasil acolhedor, sem discriminação, onde todos sorriem, são bem-vindos e se querem bem, que leva a negar os problemas que os estrangeiros encontram no dia a dia no país e impede todo esforço de escuta e reconhecimento dos problemas, para que possam ser gerenciados (Chomsky, 2007).

Marinucci (2013) indica como um agravante dessa criminalização o fato de que estereótipos contra a migração têm um caráter ainda mais criminalizante quando praticados por autoridades ou pelo discurso oficial de órgãos públicos e/ou instituições religiosas.

O processo de "criminalização", geralmente, se reproduz a partir de um círculo vicioso: determinadas ações de "contenção" da imigração são realizadas em nome da "segurança nacional", da "defesa da identidade cultural" ou da "superação da crise econômica"; essas práticas, volens nolens, acabam alimentando estereótipos e tipificações que dificultam ou impedem o delicado processo integrativo dos 
estrangeiros. A consequente escassa coesão social acaba confirmando os estereótipos e a necessidade de reproduzir com maior amplitude e intensidade as supracitadas práticas. (Marinucci, 2013, p. 1)

A criminalização, no caso de imigrantes em situação migratória irregular, pode induzi-los a uma "vulnerabilidade estrutural". Este conceito ajuda a explicar a dificuldade para migrantes em situação migratória irregular em acessar serviços. Trabalho e moradia ficam fora de seu alcance de gestão, mostrando que a dependência e a subordinação de tais sujeitos pode ser fomentada por políticas públicas, leis e práticas sociais. Políticas públicas podem ser responsáveis pela falta de equidade no acesso aos serviços e direitos básicos de migrantes e refugiados, especialmente para os que se encontram em situação migratória irregular (Gasana, 2012).

A retórica contra a migração ou a criminalização de migrantes e refugiados não é um processo para terminar com as migrações. Não há nada que se possa fazer para conseguir parar as migrações, a não ser que haja um reordenamento radical da economia mundial. Segundo Bacon:

a raiz do problema com a migração na economia global é que se trata de uma migração forçada. Uma coalizão por uma reforma deve lutar pelo direito das pessoas a escolher quando e como migrar. A liberdade de mobilidade é um direito humano. Inclusive, em um mundo mais justo, a migração continuará a acontecer porque as famílias e as comunidades atualmente estão conectadas a milhares de quilômetros e através de muitas fronteiras. Uma política migratória deveria, portanto, facilitar este movimento. (Bacon, n.d., p. 28)

\section{A modo de conclusão}

A migração é considerada um "fato social total" (Sayad, 1998). Respostas de políticas públicas aos desafios das migrações e do refúgio devem ser: interdisciplinares, integradas, contextualizadas, capazes de reconhecer e assumir a complexidade que o tema requer, sem simplismos. Um protocolo de atendimento de uma população migrante pode não corresponder ao perfil de outra comunidade ou outro fluxo no mesmo território. Origem, condições das relações bilaterais entre país de origem e de destino, história e cultura dos povos que se encontram através de deslocamentos populacionais, situações pessoais ou socioculturais contingentes do momento em que o fator migratório acontece, momento histórico em que a política é pensada ou decidida, fase do projeto migratório em que a pessoa ou o grupo se encontram, entre tantas outras variáveis, incidem de modo determinante nas condições, potencialidades e exigências de políticas adequadas de acolhida e de integração nos países de imigração. $\mathrm{O}$ que se requer são políticas que garantam acesso aos direitos assegurados a todos e também políticas que respondam às diferenças para que estas não se tornem fatores que cristalizam desigualdades discriminatórias.

Cresce mundialmente a convicção de que os protagonistas na luta por "liberdade de movimento, reconhecimento social, proteção dos trabalhadores e o direito ao refúgio" (Nyers, 2010, p. 127) são os próprios migrantes e refugiados, mesmo quando se encontram com documentação precária ou até mesmo em situação migratória irregular, o que normalmente acontece por motivos ligados a opções políticas e legislativas dos respectivos governos, não à vontade ou às estratégias migratórias dos sujeitos que se deslocam, muitas vezes com nenhuma ou escassas possibilidades de não migrar, que é um direito sempre mais afirmado e ainda não garantido. As demonstrações públicas de migrantes e defensores de direitos humanos por direitos, cidadania, liberdade e equidade em favor de migrantes e refugiados são ações claras de um protagonismo que se impõe à gestão da coisa pública. Nyers (2010) chama tais ações de "atos de cidadania" (p. 130). Quando a temática migratória não entra na agenda por vontade política, pode entrar por necessidade emergente, com complexidades e prazos muito mais complicados e exigentes. Trata-se de garantir o "direito a ter direitos" também à população que escolheu este país para viver, ao menos por um tempo, mesmo tendo nascido em outro lugar.

No relatório da comissão coordenada por Stiglitz, Sen e Fitoussi (2009) sobre desenvolvimento econômico e o progresso social, entre as principais mensagens e recomendações do estudo, os autores assinalam que, para enfrentar as desigualdades em modo integral, os países devem contar com indicadores sobre a qualidade de vida em todas as suas dimensões. O mesmo relatório aponta para a necessidade de indicadores para medir a posição em que um país se encontra em termos de "voz política", assim como sobre garantias legislativas e o papel das leis, de maneira inclusiva, para autóctones e para migrantes e refugiados, considerados como "não-cidadãos". "São necessários indicadores para avaliar quais direitos, liberdades, oportunidades e vozes podem ser exercitadas por não-cidadãos - a presença dos quais está crescendo em muitos países com o aumento das migrações internacionais" (Stiglitz, Sen, \& Fitoussi, 2009, p. 179). Ninguém é efetivamente um "João-ninguém"; o que acontece é que migrantes e refugiados, por razões concordadas entre interesses e experiências pregressas de autóctones - sociedade e seus políticos -, podem ter seu direito a ter direitos de cidadania na sociedade do país de imigração limitado por uma "hierarquia de pertença" (Nyers, 2010, p. 138). Esta faz que algumas pessoas sejam consideradas menos cidadãs que outras, por desigualdades impostas à custa do reconhecimento da mesma dignidade humana para todos.

Todas as dimensões referentes à qualidade de vida requerem modalidades apropriadas para medir as 
desigualdades, sendo que cada uma destas medidas são significativas em si mesmas, sem pretensão de absoluta prioridade sobre as demais. Segundo Stiglitz, Sen e Fitoussi (2009, p. 59), as desigualdades deveriam ser enfrentadas no que se referem a povos, grupos socioeconômicos e gerações, com especial atenção às desigualdades que emergem recentemente, como aquelas ligadas às migrações ou que as migrações colocam em evidência.
Homens e mulheres migrantes apontam para um bem-estar que não se refere à igualdade, mas à mesma dignidade e garantia de direitos, na alteridade de situações e de condições que as políticas públicas não conseguem incluir se não considerarem as desigualdades de fato.

\section{Public policies and inequalities in migration and refuge}

Abstract: The article examines, as a challenge for public policies, the theme of otherness of migrants and refugees when it is experienced or interpreted as a difference that discriminates, excludes or even criminalizes, transforming their richness into inequalities that produce and reproduce vulnerabilities. After an extensive introduction, the text unfolds in three parts: contributions to the theme from the World Report 2013 of the International Organization for Migration (IOM) on migration and from the Final Document of the Second High-level Dialogue of the United Nations on Migration and Development 2013, followed by a in-depth analysis on the criminalization of migration, considered an aspect that determines the approach to the subject. A brief conclusion emphasizes the importance of recognizing migrants and refugees as protagonists in the formulation of equitable migration policies.

Keywords: migration, human rights, inequality, migration policies.

\section{Les politiques publiques et les inégalités dans la migration et le refuge}

Résumé: Cet article analyse, comme un défi pour les politiques publiques, le thème de l'altérité des migrants et réfugiés quand celle-ci est vécue ou interprétée comme une différence qui les discrimine, exclut ou même criminalise, de façon à transformer leur richesse en inégalité qui produit et reproduit des vulnérabilités. Après une longue introduction, le texte se construit en trois parties: des contributions sur le sujet à partir du Rapport Mondial 2013 de l'Organisation International pour les Migrations sur la migration; ensuite, à partir du Document Final du II Dialogue de Haut Niveau des Nations Unies sur les Migrations et le Développement de 2013; suivi par un approfondissement sur la criminalisation de la migration, considérée comme un aspect qui détermine l'approche de la question. Une brève conclusion souligne l'importance de reconnaître les sujets migrants et réfugiés en tant que protagonistes dans la formulation de politiques migratoires égalitaires.

Mots-clés: migration, droits humaines, inégalités, équité, politiques migratoires, politiques publiques.

\section{Políticas públicas y las desigualdades en la migración y refugio}

Resumen: El artículo analiza, como desafío para las políticas públicas, el tema de la alteridad de migrantes y refugiados, cuando la misma es vivida o interpretada como una diferencia que discrimina, excluye o incluso criminaliza, transformando su riqueza en desigualdad que produce y reproduce vulnerabilidades. Después de una amplia introducción, el texto se desarrolla en tres partes: contribuciones al tema desde el Informe Mundial 2013 de la Organización Internacional para las Migraciones (OIM) sobre las Migraciones y desde el Documento Final del II Dialogo de Alto Nivel de las Naciones Unidas sobre Migraciones y Desarrollo de 2013, las cuales sigue una profundización sobre la criminalización de las migraciones, considerando un aspecto que determina el abordaje del tema. La breve conclusión enfatiza la relevancia del reconocimiento de los sujetos migrantes y refugiados como protagonistas en la formulación de las políticas migratorias que quieran tener la marca de la equidad.

Palabras clave: migraciones, derechos humanos, desigualdades, políticas migratorias. 


\section{Referências}

Ambrosini, M. (2005). Sociologia delle migrazioni. Bolonha, Itália: Il Mulino.

Assembleia Geral das Nações Unidas. (1990). Convenção internacional sobre a proteção dos direitos de todos os trabalhadores migrantes e dos membros das suas famílias. Adotada pela Resolução 45/158 da Assembleia Geral. Recuperado de http://xa.yimg.com/ kq/groups/4842518/1657921847/name/MSG696-10.doc

Assembleia Geral das Nações Unidas. (2012). Resolución 67/172 protección de los migrantes. Recuperado de http:// www.un.org/es/comun/docs/?symbol=A/RES/67/172

Assembleia Geral das Nações Unidas. (2013). Declaración del diálogo de alto nivel sobre la migración internacional $y$ el desarrollo a/68/l.5. Recuperado de http://www. un.org/es/comun/docs/?symbol=A/68/L.5

Bacon, D. (n.d.). Desplazados, desiguales y criminalizados. Luchando por los derechos de los migrantes en Estados Unidos. Fundação Rosa Luxemburgo. Recuperado de http://www.movimientomigrantemesoamericano.org/ desplazados-desiguales-y-criminalizados/

Ban Ki-Moon. (2013). Mensagem do secretário-geral da ONU para o Dia Internacional dos Migrantes de 2013. Recuperado de http://www.unicrio.org.br/rejeitar-axenofobia-e-abracar-a-migracao-e-essencial-para-odesenvolvimento-diz-secretario-geral-da-onu/

Barbagli, M. (2008). Immigrazione e sicurezza in Italia. Bolonha, Itália: Il Mulino.

Chomsky, A. (2007). They take our jobs! And 20 other myths about immigration. Boston, MA: Beacon Press.

Dal Lago, A. (Org.). (1998). Lo straniero e il nemico. Materiali per l'etnografia contemporanea. Gênova, Itália: Costa \& Nolan.

Espacio sin Fronteras. (Org.). (2013). Documento final consulta regional de la sociedad civil en Sudamérica, en preparación del diálogo de alto nivel de las Naciones Unidas sobre migración y desarrollo. São Paulo. Recuperado de http://www.cdhic.org.br/wpcontent/uploads/2013/07/Documento-Final-ConsultaSudamerica-ESF-CDHIC.pdf

Gasana, F. (2012). Irregular migrants' structural vulnerability and survival strategies. A case study in Bergen area (Master thesis in Migration and Intercultural Relations). Stavanger.

Global Coalition on Migration. (2013). Priority issues \& recommendations for the 2013 UN high level dialogue on migration \& development from the GCM-Coordinated Regional Civil Society Consultations. Recuperado de http://www.un.org/esa/population/meetings/HLD2013/ documents/Consolidated_Global_\%20Report_from_ Regional_Consultations.pdf
Global Migration Group. (2010). Statement of the Global Migration Group on the Human Rights of Migrants in Irregular Situation. Recuperado de http://www. ohchr.org/EN/NewsEvents/Pages/DisplayNews. aspx? NewsID $=10396 \&$ LangID $=\mathrm{E}$

Granma Internacional Digital. (2013). La CELAC respinge nella ONU la criminalizzazione dei migranti. Avana. Recuperado de http://www.granma.cu/italiano/ esteri/4oct-celac.html

Hammarberg, T. (2009). Rapporto del commissario per i diritti umani del Consiglio d'Europa sulla sua visita in Italia. Estrasburgo. Recuperado de http://www.meltingpot.org/ IMG/pdf/Hammarberg_Rapporto_16-2-09_.pdf

Marinucci, R. (2013). A "globalização da indiferença” e a criminalização das migrações. Recuperado de http://bit. ly/1StRTUQ

Martino, S., \& Santero, A. (2010). Letture del rapporto devianza - immigrazione dal realismo al costruttivismo. Torino. Recuperado de http://www. newsletterdisociologia.unito.it/index.php?option=com content\&view $=$ article $\&$ catid $=43 \% 3$ Aprofessionesociologo\&id $=166 \% 3$ Acriminalita-e-criminalizzazionedei-migranti-in-italia\&Itemid $=84$

Melossi, D. (2008). Il giurista, il sociologo e la "criminalizzazione" dei migranti: cosa significa "etichettamento" oggi? Studi sulla questione criminale, $3(3), 9-23$.

Nyers, P. (2010). No one is illegal between city and nation. Studies in Social Justice, 4(2), 127-143.

Organização Internacional para as Migrações. (2013). Informe sobre las migraciones en el mundo 2013 - el bienestar de los migrantes y el desarrollo. Recuperado de http://publications.iom.int/bookstore/index.php?main page $=$ product_info\&cPath $=37 \&$ products_id $=1019 \& z e n$ $\mathrm{id}=3$ piouecbtuhq $31 \mathrm{~m} 9 \mathrm{ol} 43 \mathrm{q} 1 \mathrm{lvc} 4$

Sayad, A. (1998). A imigração ou os paradoxos da alteridade. São Paulo, SP: EDUSP.

Stiglitz, J. E., Sen, A., \& Fitoussi, J.-P. (2009). Report by the commission on the measurement of economic performance and social progress. Recuperado de www. stiglitz-sen-fitoussi.fr

Uzeta, A. T. (n.d.). La condición jurídica y derechos de los migrantes indocumentados. Apuntes sobre la Opinión Consultiva OC-18/03 solicitada por México a la Corte Interamericana de Derechos Humanos. Recuperado de http://epikeia.leon.uia.mx/old/numeros/06/epikeia06la_condicion_juridica.pdf

Recebido: 06/03/2014

Revisado: 17/06/2014

Aceito: 07/07/2014 